Article

\title{
Feedstocks of Aluminum and 316L Stainless Steel Powders for Micro Hot Embossing
}

\author{
Omid Emadinia ${ }^{1,2, *(\mathbb{D}}$, Maria Teresa Vieira ${ }^{2}$ (D) and Manuel Fernando Vieira ${ }^{1,3}$ (D) \\ 1 CEMMPRE, Centre for Mechanical Engineering, Materials and Processes, Department of Metallurgical and \\ Materials Engineering, University of Porto, Rua Dr. Roberto Frias, 4200-465 Porto, Portugal; \\ mvieira@fe.up.pt \\ 2 CEMMPRE, Centre for Mechanical Engineering, Materials and Processes, Department of Mechanical \\ Engineering, University of Coimbra, Rua Luís Reis Santos, 3030-788 Coimbra, Portugal; \\ teresa.vieira@dem.uc.pt \\ 3 INEGI-Institute of Science and Innovation in Mechanical and Industrial Engineering, \\ Rua. Dr. Roberto Frias, 4200-465 Porto, Portugal \\ * Correspondence: omid.emadinia@fe.up.pt; Tel.: +35-192-434-2143
}

Received: 15 October 2018; Accepted: 23 November 2018; Published: 28 November 2018

check for updates

\begin{abstract}
In metal powder, shaping the preparation and characterization of the feedstock is an aspect commonly recognized as fundamental. An optimized composition is required to ensure the successful shaping of the feedstock. In this study, a commercial binder system, pure aluminum and 316L austenitic stainless-steel powders were used for micro hot embossing. The optimization process revealed that powder characteristics such as shape and the stability of the torque mixing, were important parameters. Manipulating the feedstock composition by adding multi-walled carbon nanotubes or stearic acid or using a higher powder concentration considerably influenced the torque mixing values. The steady state of torque mixing was achieved for all feedstocks. This torque behavior indicates a homogeneous feedstock, which was also confirmed by microscopic observations. Nevertheless, an extruding process was required for greater homogeneity of the aluminum feedstocks. The presence of the carbon nanotubes increased the homogeneity of green parts and reduced microcrack formation. The roughness was essentially dependent on the feedstock composition and on the plastic deformation of the elastomer die. Shaping the prepared feedstocks (with or without carbon nanotube) was achieved by the optimized powder concentrations and it did not increase by the stearic acid addition.
\end{abstract}

Keywords: carbon nanotubes; feedstock; homogeneity; metallic powders; micro hot embossing; shaping

\section{Introduction}

Micro hot embossing is a well-known replicating technique for the production of polymeric micro components through which large scale production of substrates with micropatterns (and even in nanoscales) is feasible, being reported aspect ratios from 0.06 up to 2.00. For industrial applications three manufacturing methods are applied: plate to plate, roll to plate and roll to roll. The shaping is carried out by pressing with a determined force the mould into a substrate at a temperature at which the material (thermoplastic) behaves as a viscous flow [1]. Micro hot embossing is interesting since the application of laboratory machines helps to reduce the interval between product development and production [2]. It has also been adapted as a metal powder processing technique [3], which involves feedstock (powder-binder mixture) preparation, shaping to obtain a so-called green part, debinding and sintering to attain final product. Major differences between micro hot embossing applied to polymers 
and metal feedstocks include high series production for polymers and low series for metals, in addition, shaping is achieved using a hard mould to promote replication on the surface of the polymeric substrate, and an elastomer die for the metallic feedstock. Related studies reported the shaping of 316L stainless steel, $\mathrm{Cu}, \mathrm{Fe}-\mathrm{Ni}$, and WC-Co feedstocks [3-7]. Some feedstocks were prepared based on the critical powder volume concentration (CPVC) having a value slightly smaller than CPVC, so-called optimized feedstocks. Determination of this value was reported by using torque mixer equipment and by plotting the torque values of the softened binder and powder mixture against the powder concentrations. The CPVC is the volume at which the slope of the torque growth increases suddenly [8,9].

This study evaluated the $\mathrm{Al}$ and AISI 316L feedstock preparation based on the CPVC criteria and verified the optimized compositions by shaping green micro-components. Multi-walled carbon nanotubes (MWCNTs) were also used for some feedstocks, this carbon allotrope was used because it is strong and stiff, widely used for strengthening metal matrices [10]. This being the case, shaping metal matrix nanocomposites through micro hot embossing will be evaluated using large amount of feedstock that needs the dispersion of MWCNTs and metallic powders in large scale, in a similar manner to what was done in micro powder injection moulding ( $\mu$ PIM) [11,12].

A torque rheometer was used for the feedstock preparation. It is expected that the feedstocks will be homogeneous when the torque reaches a steady state [13]. The homogeneity of the feedstocks was also evaluated by scanning electron microscopy (SEM) observations. The torque value represents the energy required for mixing a certain volume of materials under specified processing conditions, and it can be used to evaluate the behaviour of the feedstock during mixing. It can further provide information on viscosity, in terms of powder concentration (the higher the torque value, the more viscous the mixture [13]), or feedstock composition manipulation (the addition of MWCNTs will increase feedstock viscosity due to the high surface area of the nanotubes). The SEM and infinite focus microscopy (IFM) were used to evaluate the shaping of green micro hot embossed parts.

\section{Materials and Methods}

AISI 316L stainless steel powder $(0.012 \%$ C, $0.57 \% \mathrm{Si}, 2.40 \% \mathrm{Mo}, 17.10 \% \mathrm{Cr}, 11.10 \% \mathrm{Ni}$ and $1.17 \%$ $\mathrm{Mn}$ ) and pure $\mathrm{Al}$ powders (99.80\% purity), a commercial binder material (called M1) composed of polyolefin waxes, and MWCNT were used (Table 1).

Table 1. Suppliers and characteristics of input materials.

\begin{tabular}{|c|c|c|c|c|c|}
\hline Material & Supplier & $\mathrm{D}_{50}(\mu \mathrm{m})$ & $\begin{array}{l}\text { Density } \\
\left(\mathrm{kg} / \mathrm{m}^{3}\right)\end{array}$ & $\begin{array}{l}\text { Specific Surface Area } \\
\qquad\left(\mathrm{m}^{2} / \mathrm{kg}\right)^{1}\end{array}$ & Aspect Ratio \\
\hline AISI 316L & Sandvik Osprey Ltd ${ }^{2}$ & 3.5 & 7937 & 2120 & $\sim 1$ \\
\hline MWCNT & Fibermax Composites 4 & - & 2010 & - & \\
\hline M1 & Atect $^{\circledR}$ Corporation ${ }^{5}$ & - & 970 & - & \\
\hline
\end{tabular}

${ }^{1}$ This value was given along with the results of particle size analyses made by Malvern equipment. We report these values, although they are not as accurate as those obtained by the gas absorption method. ${ }^{2}$ Sandvik Osprey Ltd., West Glamorgan, UK. ${ }^{3}$ Thermo Fisher (Kandel) GmbH, Karlsruhe, Germany. ${ }^{4}$ Fibermax Ltd. Agria Volou, Greece. ${ }^{5}$ Atect Corporation, Shiga, Japan.

The density, morphology (Figure 1a,b) and particle size distribution (PSD) of the powders (Figure 1c) were analyzed by Helium pycnometer (Micromeritics AccuPyc 1330, Micromeritics Instrument Corporation, Norcross, GA, USA), SEM, backscattered electron (BSE) and secondary electron (SE) modes, (FEI-Quanta 400 FEG equipment, FEI Company, Hillsboro, OR, USA), and laser diffraction analyzer (Mastersizer 3000, Malvern Instruments Limited, Worcestershire, UK) equipment, respectively. Thermal properties of the binder material (Figure 1d) were analyzed by a thermal analyzer (Setaram SetSys equipment, Setarem Instrumentation, Caluire, France), it was carried out in Argon (99.999\% purity) atmosphere at heating-cooling rates of $10{ }^{\circ} \mathrm{C} / \mathrm{min}$. Feedstock processing was performed on a Brabender Plastograph (Brabender ${ }^{\circledR G m b H}$ \& Co. KG, Duisburg, Germany), with a chamber volume of $42 \mathrm{~cm}^{3}$ and a torque rheometer with twin Z-blades. A single screw extruder 
Brabender equipment was used to eliminate the porosities left inside feedstocks prepared by the Plastograph, if necessary. The Alicona IFM G4 equipment (Alicona Imaging GmbH, Graz, Austria) determined two surface roughness parameters: Sa which is the arithmetical average of the absolute values of the roughness profile, and $\mathrm{Sz}$ as the difference between the highest peak and the deepest valley in the analyzed area.

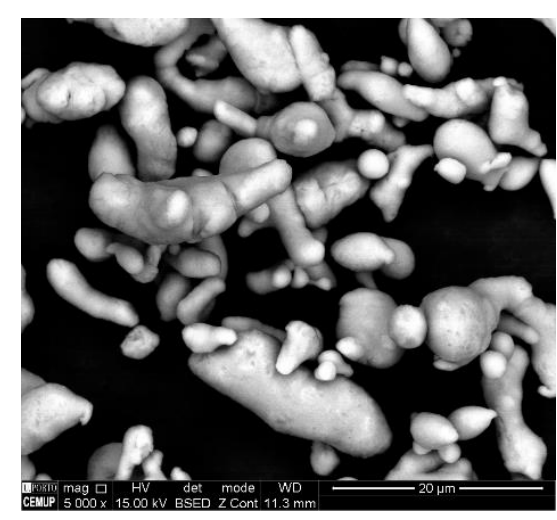

(a)

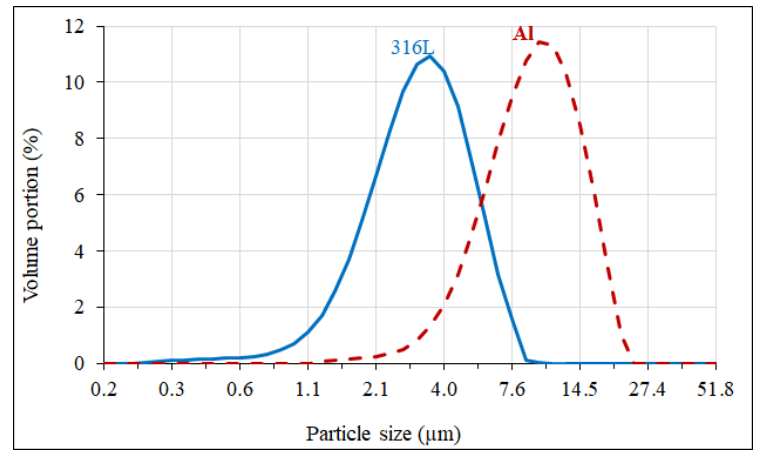

(c)

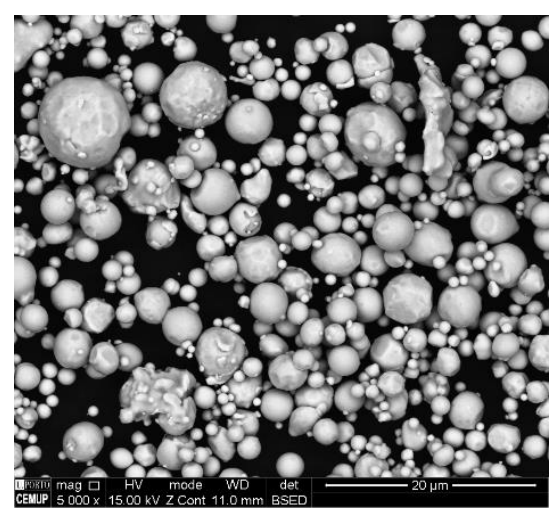

(b)

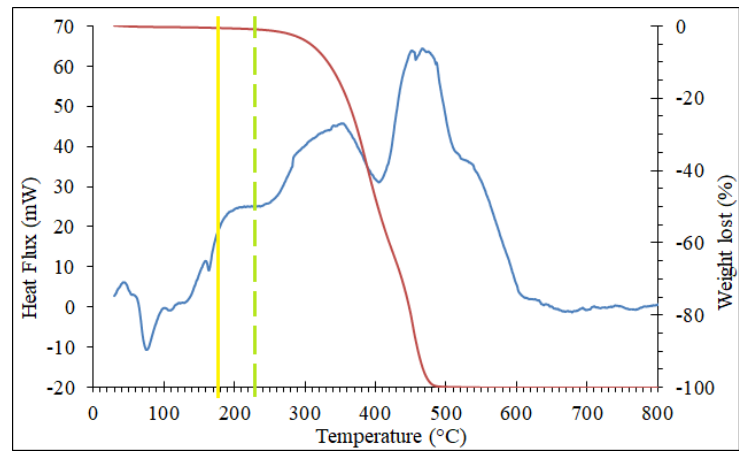

(d)

Figure 1. SEM/SE images of (a) $\mathrm{Al}$ and (b) 316L powders; (c) particle size distribution (PSD) graphics of the powders; (d) differential scanning calorimetry and thermogravimetric analysis graphs of the binder; the solid and dashed lines illustrate the mixing and shaping temperatures, respectively.

For this study, $\mathrm{Al}$ and 316L feedstocks, with and without $1 \mathrm{vol} \%$ of MWCNT, were used. The binder and powder were mixed inside the Plastograph chamber. First, the binder (in a proper volume concentration) was melted inside the chamber (at $175^{\circ} \mathrm{C}$ for $5 \mathrm{~min}$ ) and then metal powders (or powder-MWCNT mixtures) were added. What regards the determination of CPVC, this started with the addition of 50 vol.\% of powder to the pre-melted binder and continued through the increments of 1 vol.\% powder until the chamber became full; the minimum mixing time for each sequence was considered five min (similar to previous study [14]). Since the Plastograph equipment showed the torque value in real time, it was only proceeded for the next batch when the torque value stabilized (aluminum powders mixing time frequently exceeded the previously fixed five min). After selecting the optimized composition (CPVC value subtracted by one) through this method, the feedstock preparation involved the addition of three batches of powders (or metallic powders-MWCNT mixtures) to the pre-melted binder. What regards the time required for feedstock preparation, it was decided to stop mixing when the mixture torque values reached the steady state. The effect of adding stearic acid (SA) as a diluting agent was also analyzed. The SA was mixed with the powder on a Turbula shaker for $30 \mathrm{~min}$ before being added to the binder. Pristine MWCNTs were highly entangled (Figure 2a) and were broken apart as much as possible with dispersing conditions that avoid damaging the nanotubes. A one step dispersion method was performed involving simultaneously 
sonicating (20,400 rpm) the powder and MWCNT in isopropanol for $15 \mathrm{~min}$, draining and drying at $80^{\circ} \mathrm{C}$ for $1 \mathrm{~h}$ [15]. Al-MWCNT and 316L-MWCNT mixtures (Figure 2b,c) were produced through this method before being added to the Plastograph chamber. Torque mixing was carried out at $30 \mathrm{rpm}$ and $175{ }^{\circ} \mathrm{C}$ until stabilization (constant torque value) was achieved. Three batches were prepared for each aluminum feedstock, and two batches for each stainless steel. Extruding the Al feedstocks was also performed at $15 \mathrm{rpm}$ and $175^{\circ} \mathrm{C}$. All aluminum and stainless-steel feedstocks were granulated and sieved before shaping. Granulation was performed by a blender equipment through three sequences of blending and sieving (in a total of one-minute blending), granulated particles were sieved in each sequence by a laboratory test sieve of $500 \mu \mathrm{m}$ aperture size (Retsch®Haan, Germany).

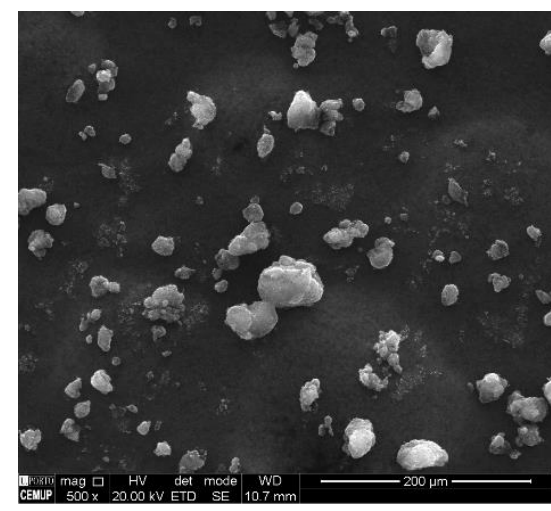

(a)

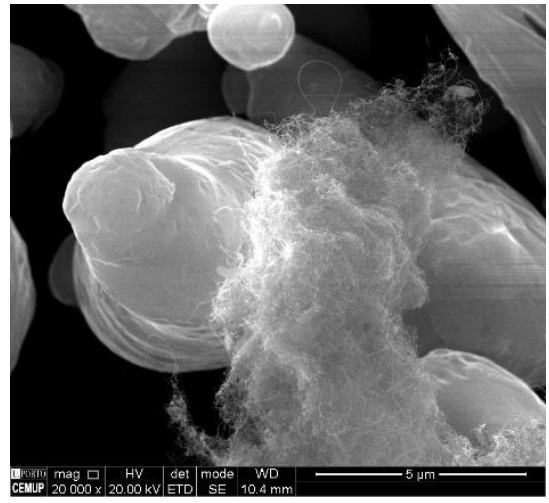

(b)

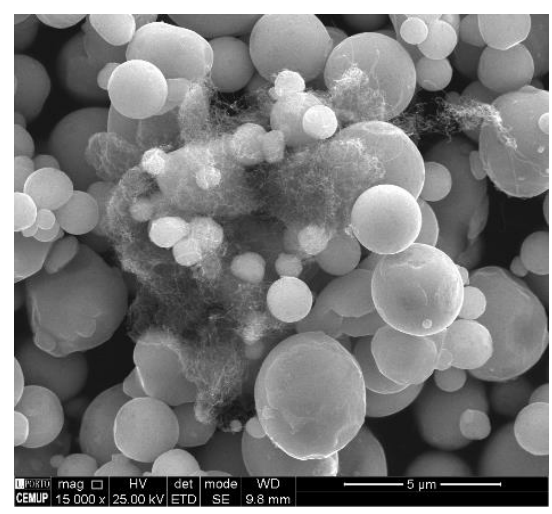

(c)

Figure 2. SEM/SE images of (a) pristine MWCNTs, (b) Al-MWCNTs and (c) 316L-MWCNTs mixtures for feedstock preparation.

The homogeneity of feedstock was evaluated by the stabilization of the torque mixing value and by SEM observations. In SEM analysis, the homogeneity of feedstocks and green parts is evaluated by the distribution of dark regions (representing higher binder concentration).

Feedstocks were shaped into two different green parts: a microblind-flange and microchannel-halfflanges (Figure 3 and Table 2). The shaping facilities included a uniaxial press LIOYD LR 30K equipment (AMETEK (GB) Ltd., West Sussex, UK) assembled with an infrared radiation furnace, it was carried out at $230{ }^{\circ} \mathrm{C}, 8.5 \mathrm{MPa}$ or $11.3 \mathrm{MPa}$ for 15,30 or $45 \mathrm{~min}$ in air. This shaping temperature ensures maximum replication without severely damaging the elastomer die. Two elastomer materials were used: a dark blue one with $46 \pm 1$ Shore A hardness (HB FLEX $5550 \mathrm{~A}+\mathrm{B}$ ), and a transparent one with $38 \pm 1$ Shore A hardness (HB FLEX RTV2 T4 S A + B). These materials were supplied by HB Quimica, LDA (HB Química, Matosinhos, Portugal). The elastomer hardness was measured by Teclock GS-719N equipment (Teclock Corporation, Nagano, Japan) at room conditions. 


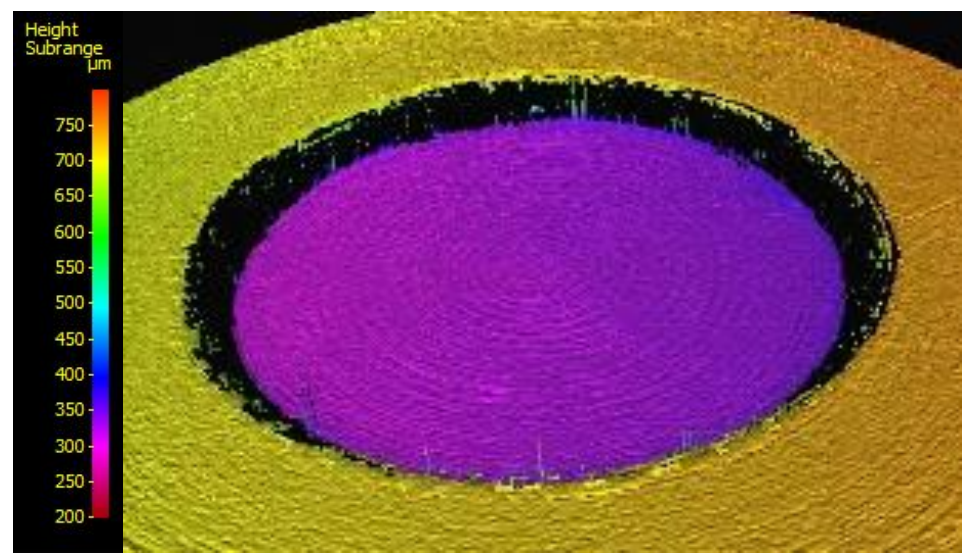

(a)

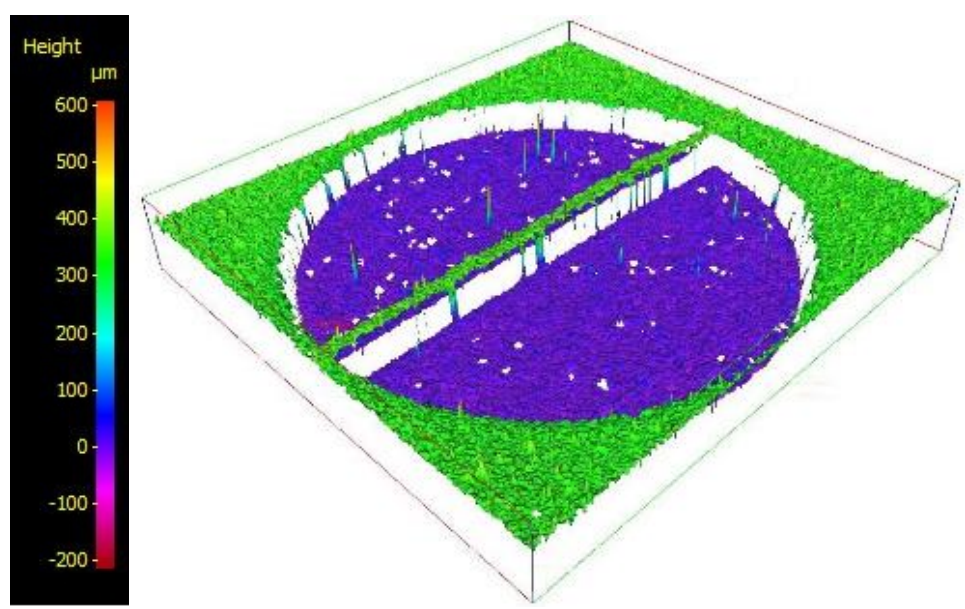

(b)

Figure 3. Configurations and roughness maps (obtained by infinite focus microscopy (IFM) analyses) of the dark blue elastomer die and the transparent elastomer die used for replicating (a) microblind-flange and (b) microchannel-half-flanges green parts.

Table 2. Dimensional characteristics (in $\mu \mathrm{m}$ ) of the dies illustrated in Figure 3.

\begin{tabular}{ccccccc}
\hline Die & Diameter & Height & Maximum Width & Minimum Width & Sa & Sz \\
\hline Dark blue elastomer & 4918 & $\sim<400$ & - & - & 2 & 36 \\
Transparent elastomer & 4896 & $355 \pm 9$ & $326 \pm 10$ & $204 \pm 13$ & 9 & $680^{6}$ \\
\hline
\end{tabular}

${ }^{6}$ This value is affected by the column-like features appeared on the blue surface of the elastomer die in Figure $3 \mathrm{~b}$ and these should be artifacts.

\section{Results and Discussion}

\subsection{Optimization Process: Effects of Powder Type}

According to Figure 4 the graphs demonstrate 59 and 61 vol.\% as the CPVC values for the $\mathrm{Al}$ and 316L feedstocks because at these points the slope of the torque growth is greater than for the previous points, being this more pronounced for the 316L system. Although the 316L powder has a smaller PSD than the Al, it obtained a larger CPVC. This should be the consequence of having a shape factor very close to one (spherical) unlike the $\mathrm{Al}$ powder which has a higher factor (see Figure 1). This is consistent with a mostly accepted statement concerning the effect of powder shape on viscosity [16] (p. 73). Another study further showed that a powder size reduction (by half) did not influence the CPVC [17]. 


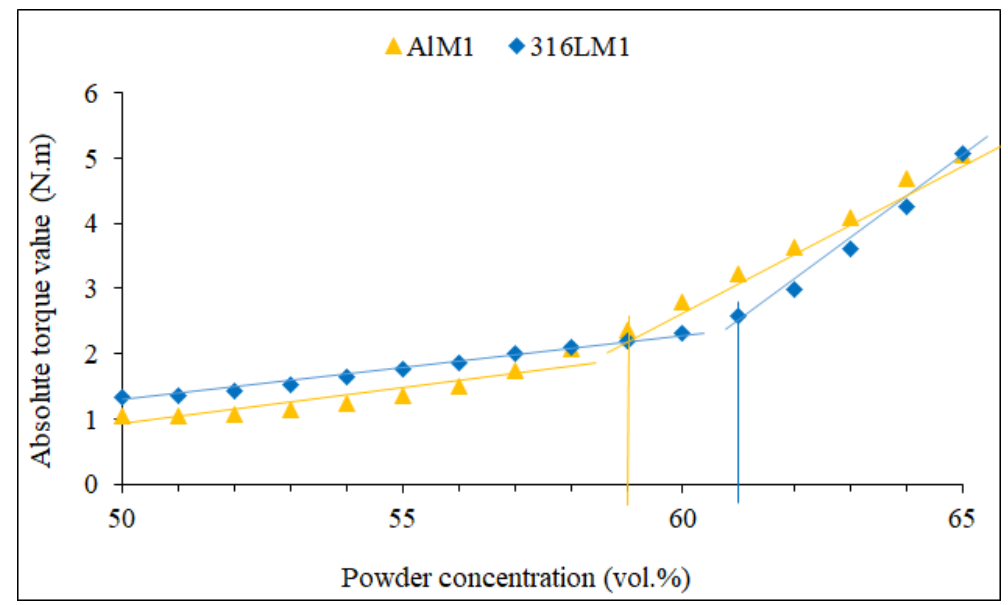

Figure 4. Determination of critical powder volume concentration (CPVC) through the optimization process (common approach): torque values function of powder increments (Al and 316L) to the M1 binder, using Z-blade mixer at $30 \mathrm{rpm}, 175^{\circ} \mathrm{C}$ and the atmospheric pressure $(101 \mathrm{kPa})$. Yellow and blue intersects represent CPVC values.

Regarding the torque mixing value as the function of powder concentration, the graph illustrated in Figure 4 presents two regions: in the first region, below 59 vol.\% powder concentration, the torque values of the $316 \mathrm{~L}$ mixture are higher than those of the $\mathrm{Al}$, while in the second one this order is inverted. In the first region, the difference can be attributed to the particle size, i.e., the finer powder (316L) has higher viscosity [16] (p. 73). This effect was expected to be pronounced for higher powder concentrations due to the increase in the friction caused by powder interactions [18]. However, this difference is practically constant up to a powder concentration close to $59 \%$, after which the $\mathrm{Al}$ torque value grows faster with the powder concentration and exceeds the $316 \mathrm{~L}$ value. This behavior can be attributed to the influence of particle shape at larger powder contents, this being the case, irregular shaped particles will cause viscosity increase due to presenting larger friction [16] (p. 73). Moreover, the experiment time for the determination of CPVC was longer for $\mathrm{Al}$ (120 min) than for 316L (80 min). This determination process was monitored visually in real time, and it was not needed to extend the $5 \mathrm{~min}$ mixing time for the incremental sequences of the 316L. This difference could be attributed to a shorter stabilization time required for the $316 \mathrm{~L}$ powders. Although the $316 \mathrm{~L}$ powders have higher surface area, meaning the 316L powders need larger mixing time, to interact with binder and stabilization, than the $\mathrm{Al}$ powders, the particle shape should have diminished the particle size effect [18]. Thus, it is expected that the 316L feedstock can even be homogenized faster than that of the Al.

From the CPVC points onwards, the torque increase rate of the 316L-binder system exceeded that of the Al-binder. This can be attributed to the particle interactions at larger powder concentrations, being affected by the powder's characteristics.

The difference between the CPVC value of the $316 \mathrm{~L}$ in this study and related studies, using similar PSD, which reported values close to $66 \%[7,14,17,19]$, can be attributed to the use of different binder type or processing conditions (mixing temperature or speed). The influence of these differences is seen in a related study in which a CPVC of $61 \%$ was reported for a 316L stainless-steel powder [20].

For the $\mathrm{Al}$ powder the determination of the CPVC was not as easy as that of the $316 \mathrm{~L}$. In fact, for this material the determination of a point at which a sudden torque increase occurred was difficult. To confirm the CPVC values based on Plastograph approach (Figure 4), a complementary study was performed. Figure 5 illustrates the absolute torque increases $(Y$ axes) for the continuous increments of 1 vol.\% of metal powder ( $X$ axes). Each square highlights two increments for which the increase in torque is evident for the intermediate concentration. In relation to the $\mathrm{Al} \mathrm{system,} \mathrm{the} \mathrm{increase} \mathrm{in}$ torque shows some fluctuations thus, two orange squares are indicated as the zones where the possible 
values of CPVC are detected (59 and 63 vol.\%). For stainless steel, the CPVC value is 61 vol.\%. What regards the optimized compositions, that are smaller than the corresponding CPVCs, the optimum powder volume concentration of $\mathrm{Al}$ should be validated through the production of green parts by feedstocks with 58 and 62 vol.\% of powder concentration. Regarding the 316L powder, feedstock with 60 vol.\% powder can guarantee the replicability of green part, this volume is also consistent with previous study [21].

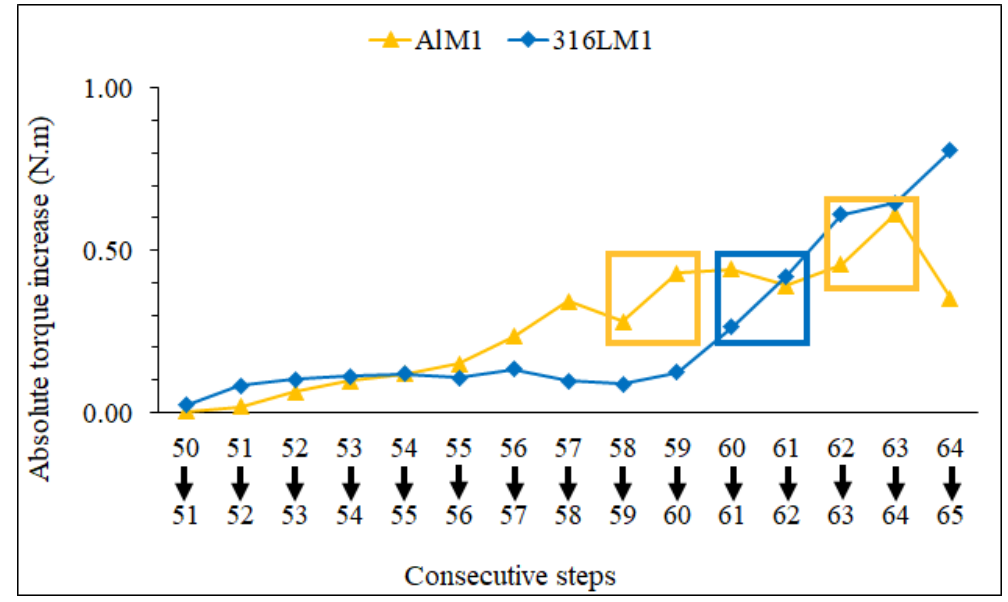

Figure 5. Determination of CPVC through the optimization process (complementary evaluation): torque increases between every two consecutive steps versus the corresponding powder addition steps.

\subsection{Feedstocks: Effect of Composition on Torque Values}

Table 3 presents the acronym and some characteristics of the $\mathrm{Al}$ and 316L feedstocks. The major result concerns the effect of increasing powder concentration or adding MWCNT onto the increase in the feedstocks' torque values, which is consistent with other studies [22-24]. As expected, the increase of powder concentration lead to higher torque value [25]; the feedstocks with 65 vol.\% of powders presented the maximum torque values.

Table 3. Acronyms, compositions and mean torque values required for mixing of feedstocks. The mean values and the standard deviations were measured from the stabilized regions (after $12 \mathrm{~min}$ of time) of the torque mixing curves obtained by the feedstock preparation.

\begin{tabular}{ccccc}
\hline Acronym & Constituents & Concentration (vol.\%) & Torque (Nm) & Standard Deviation \\
\hline Al58M1 & Al \& M1 & $58: 42$ & 2.66 & 0.06 \\
Al-MWCNT58M1 & Al, CNT \& M1 & $58(1): 42$ & 3.92 & 0.04 \\
Al-MWCNT58M1SA5 & Al, CNT, M1 \& SA & $58(1): 42(5)$ & 1.97 & 0.07 \\
Al62M1 & Al \& M1 & $62: 38$ & 3.63 & 0.08 \\
Al62M1SA1.6 & Al, M1 \& SA & $62: 38(1.6)$ & 2.00 & 0.05 \\
Al62M1SA5 & Al, M1 \& SA & $62: 38(5)$ & 1.58 & 0.04 \\
Al65M1 & Al \& M1 & $65: 35$ & 5.05 & 0.13 \\
316L60M1 & 316L \& M1 & $60: 40$ & 2.76 & 0.05 \\
316L-MWCNT60M1 & 316L, CNT \& M1 & $60(1): 40$ & 3.79 & 0.07 \\
316L65M1 & 316L \& M1 & $65: 35$ & 5.06 & 0.09 \\
\hline
\end{tabular}

For the Al-binder system the effect of 1 vol.\% MWCNT is more pronounced than the increase in the powder content by 4 vol.\%. The addition of SA decreased the viscosity of the feedstocks. However, the increase in the SA from $1.6 \%$ to $5.0 \%$ did not result in a strong viscosity reduction, which is consistent with related studies [21,26,27]. According to the torque mixing values (Table 3), it is expected that the feedstocks with smaller values will lead to a better shaping. Table 3 also shows no significant differences between the standard deviations, except for A165M1. The microstructural analyses of feedstocks, prepared by the torque mixer, show the presence of large porosities when 
SA was added to the feedstock (Figure 6). This indicates that the porosity may assist the reduction in viscosity.

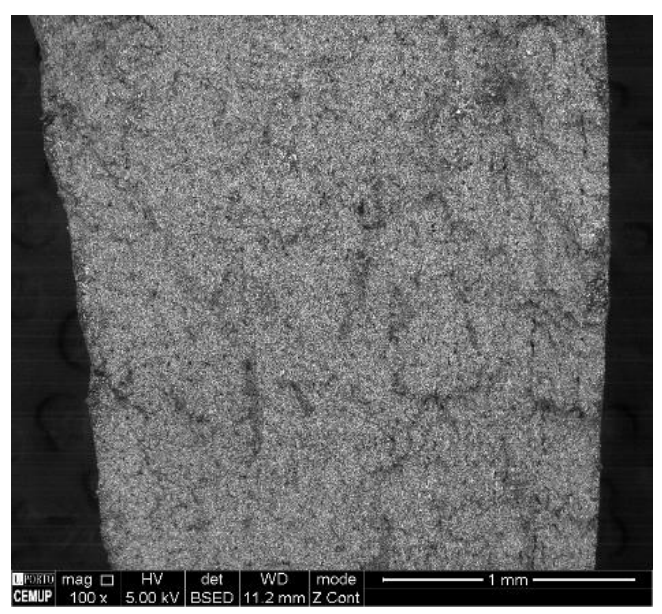

(a)

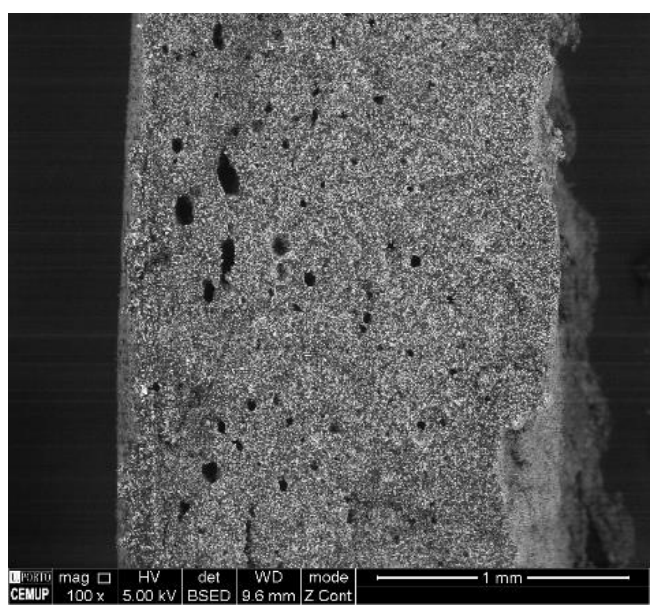

(b)

Figure 6. SEM/backscattered electron (BSE) images of (a) Al62M1 and (b) Al62M1SA1.6 feedstocks after torque mixing.

\subsection{Feedstocks, Torque Stability and Homogeneity}

Figure 7a illustrates the torque variations of Al58M1, Al-MWCNT58M1 and Al-WCNT58M1SA5 feedstocks. The unstable initial period belongs to Al-MWCNT58M1 and the great fluctuation could be attributable to the dispersion and interaction of the MWCNT with the binder during the earliest mixing period. The addition of SA delayed the stabilization stage, however, all $\mathrm{Al}$ feedstocks reached a nearly constant torque value, usually called a steady state, after 17 min which will be considered as a reference mixing time in this study.

Microstructural observations from A158M1 feedstock prepared by Plastograph after mixing (Figure 8a) highlighted the need for further mixing, which was performed by a single screw extruder and led to better homogeneity and reduction of porosities (Figure 8b). Subsequent microstructural analysis confirmed no differences in the dispersion of the constituents of feedstocks. Although some authors reported a good wettability of CNTs in some polymeric materials feedstocks, such as polypropylene and polyethylene glycol [28], in the present study the MWCNT agglomerations still existed after torque mixing and extrusion, with or without SA (Figure $7 \mathrm{~b}, \mathrm{c}$ ), due to the different polymeric materials constituting the binder.

The torque changes during the mixing of the 316L60M1 and 316L-MWCNT60M1 feedstocks are shown in Figure 9a. The addition of the MWCNT increased torque values and delayed torque stabilization. This last difference can be attributed to the untangling of MWCNTs during torque mixing. The untangling is not complete after $25 \mathrm{~min}$, since the microstructure revealed the presence of nanotube clusters (Figure 9b). The steady state was achieved after mixing for $17 \mathrm{~min}$ and it was maintained (which is more pronounced for 316L60M1 than 316L-MWCNT60M1) for an additional eight more $\mathrm{min}$ ( $25 \mathrm{~min}$ in total) to improve homogenization. Microscopy observations confirmed that the 316L feedstocks made by the torque mixer were homogeneous and did not need any extruding treatment. The comparison of torque values for $\mathrm{Al}$ and $316 \mathrm{~L}$, with and without MWCNTs, shows a similarity in values between them (Figure 9c), which highlights the effect of using the same binder system for all feedstocks [29]. 


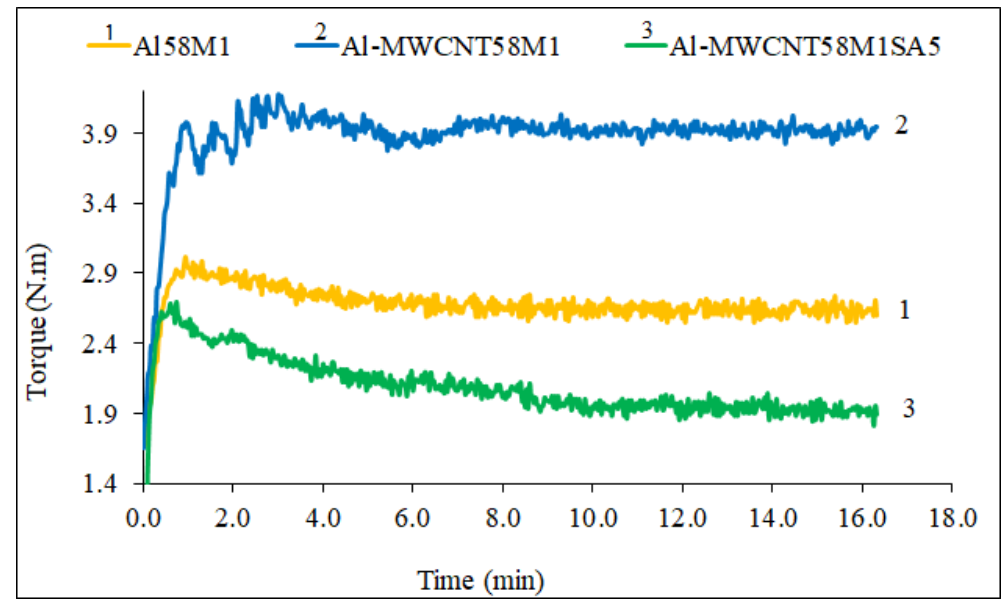

(a)

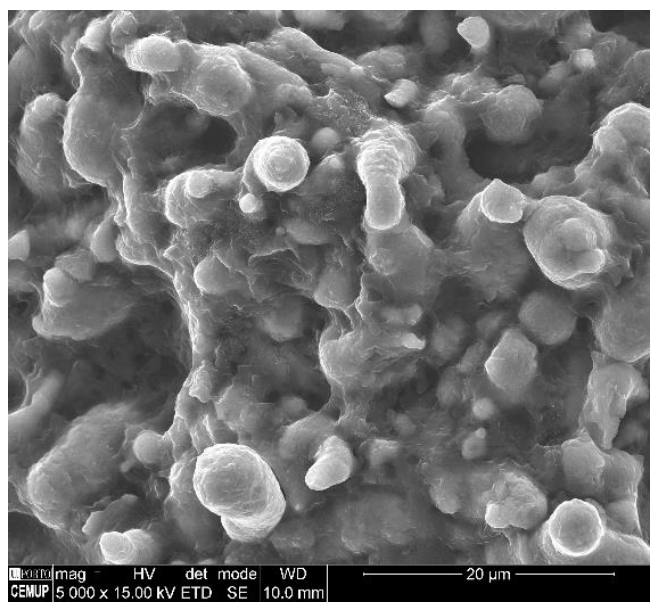

(b)

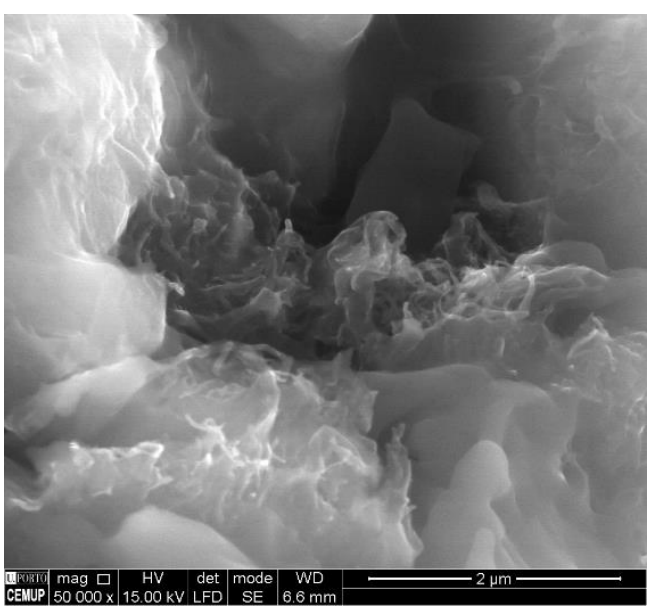

(c)

Figure 7. (a) Torque variation during mixing Al feedstocks (Al58M1, Al-MWCNT58M1 and Al-MWCNT58M1SA5) during mixing; SEM/BSE images showing (b) the distribution of the powder-binder-MWCNTs in Al-MWCNT58M1 and (c) the presence of the MWCNT aggregations in the binder of same feedstock.

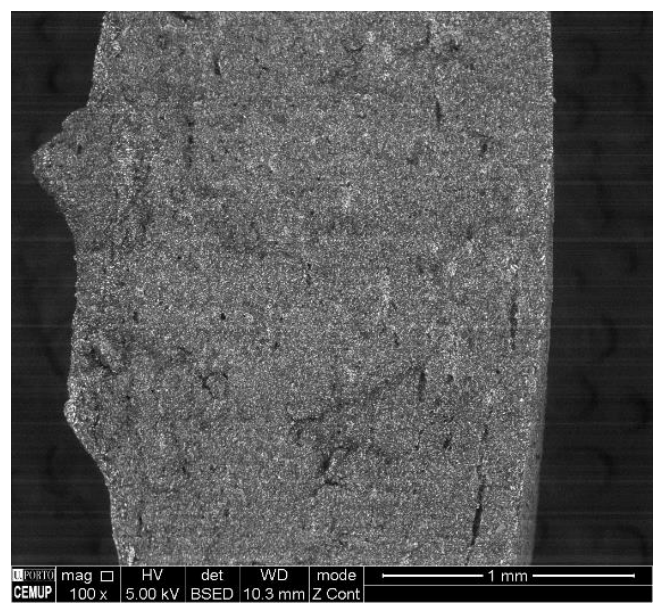

(a)

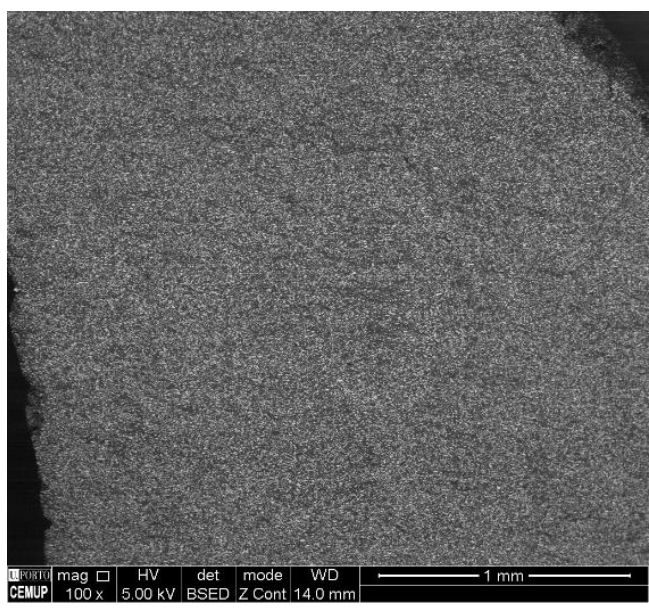

(b)

Figure 8. Microscopy observations (SEM/SE) from AL58M1 after preparation by (a) Plastograph and (b) extrusion for porosity elimination. 


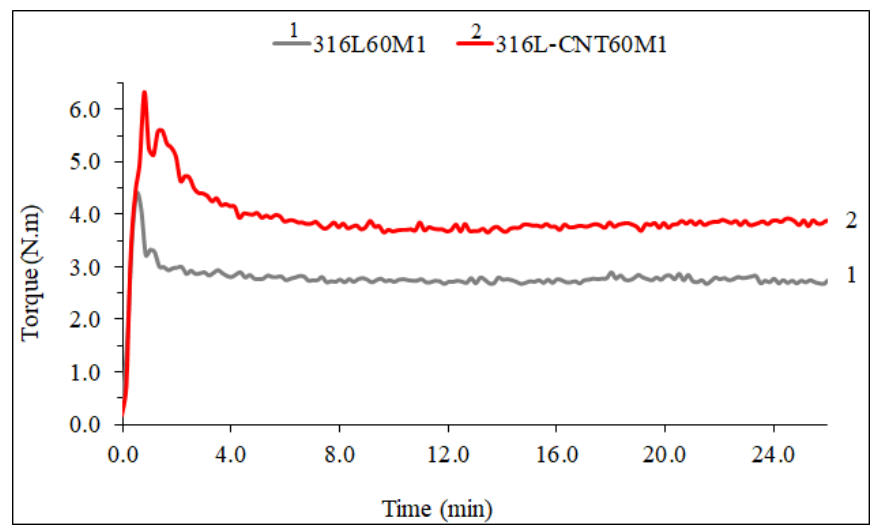

(a)

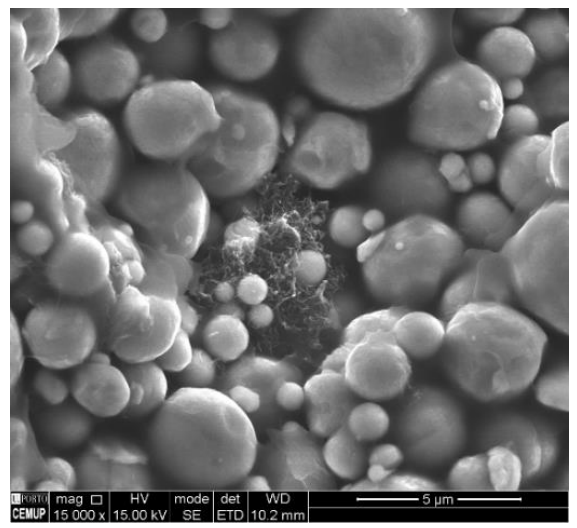

(b)

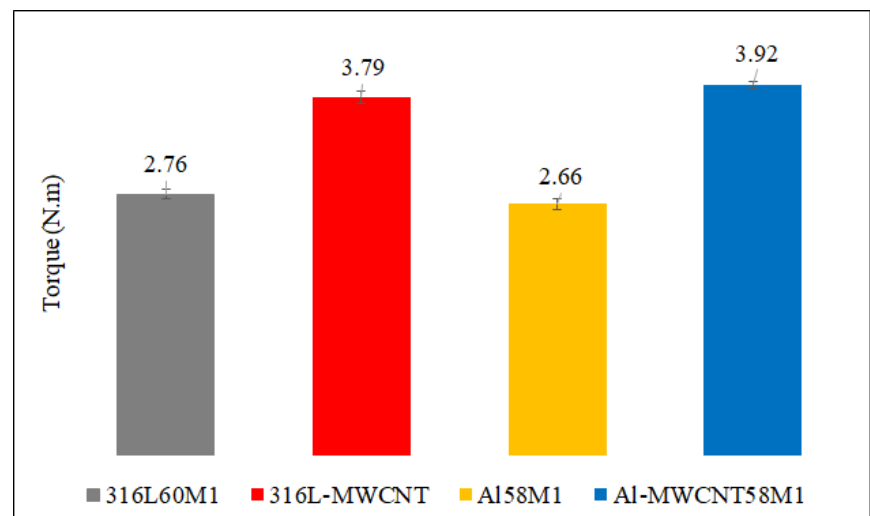

(c)

Figure 9. (a) Torque variation during mixing 316L and 316L-MWCNT feedstocks; (b) SEM/SE image of the 316L-MWCNT60M1 feedstock; (c) comparison of the torque values of the optimized Al and 316L systems.

\subsection{Shaping Feedstocks}

Microscopy observations of green microblind-flange revealed that the sharp edge and concentric rings were replicated by the Al58M1, with and without MWCNT (Figure 10a,b), though the Al-MWCNT58M1 feedstock required a larger torque mixing value, these rings were not replicated by Al62M1 feedstock and this found a strong waviness surface (Figure 10c). These waviness surfaces represent non-replicated feedstock particulates. Therefore, the metallic powder concentration of $62 \mathrm{vol} . \%$ is not suitable for micro-hot embossing. Although the addition of SA resulted in a decrease in viscosity (Table 3), the shaping did not increase and the waviness structure were appeared on the surfaces of Al-MWCNT58M1SA5, Al62M1SA1.6 and A162M1SA parts (Figure 10d-f). Therefore, in this 
microfabrication process the powder concentration, rather than the viscosity, determines the success of the replication.

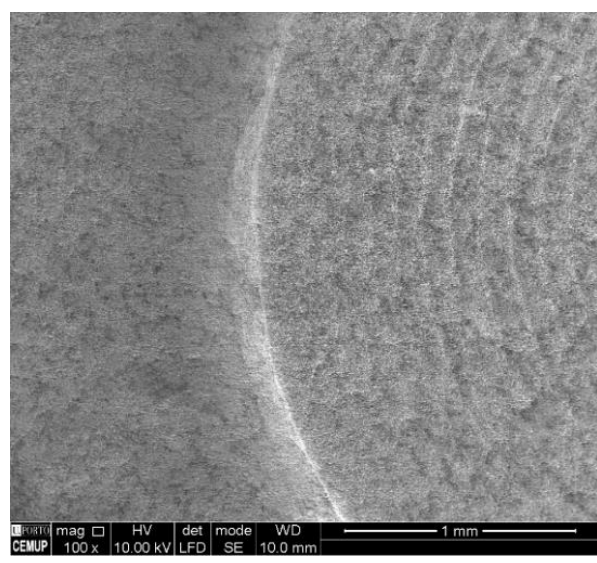

(a)

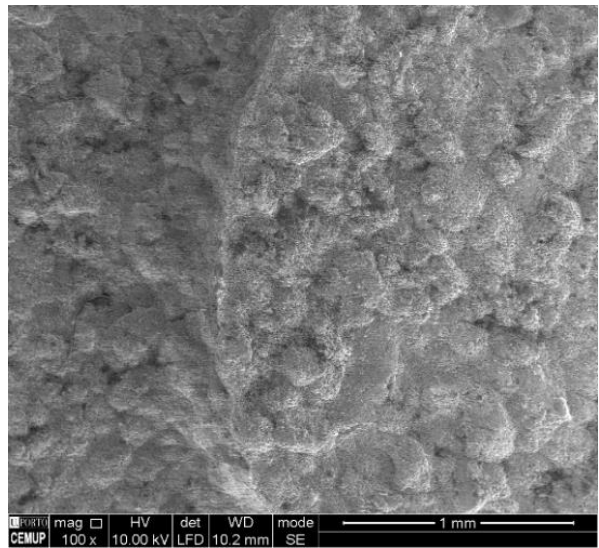

(c)

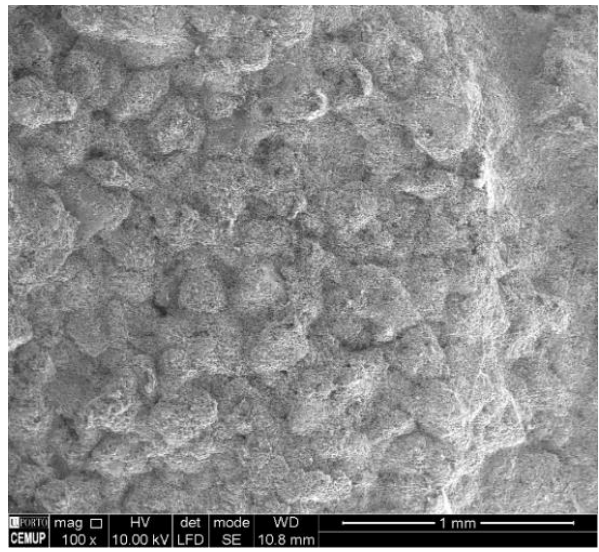

(e)

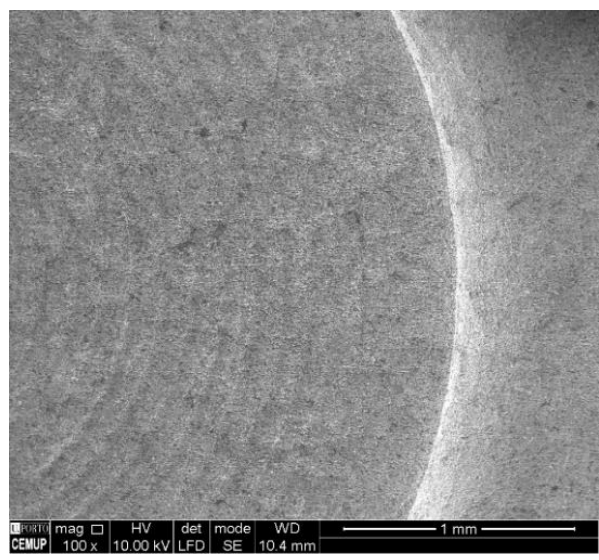

(b)

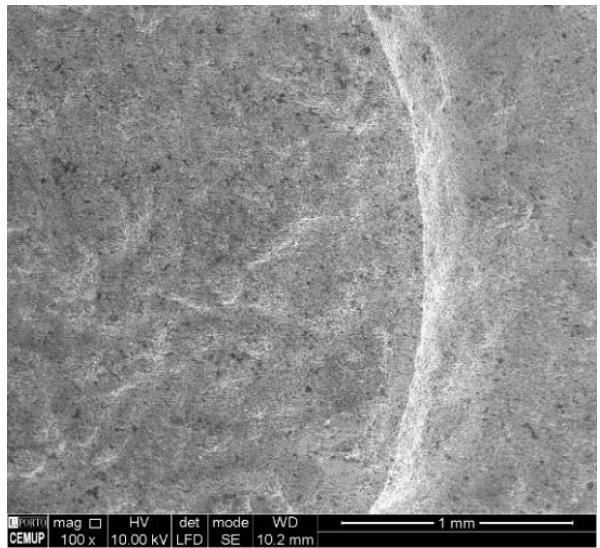

(d)

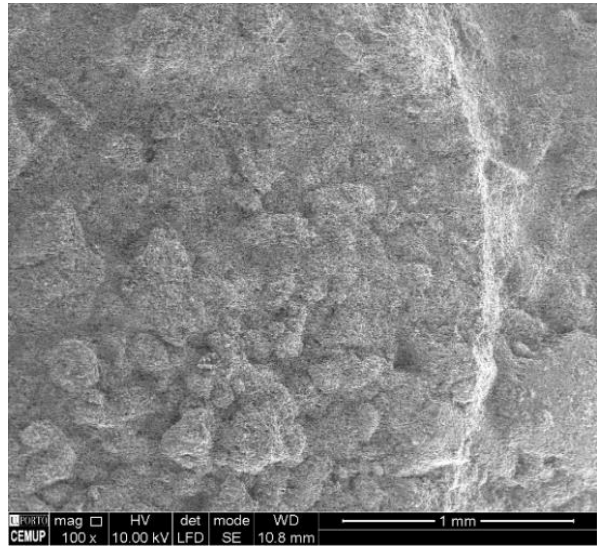

(f)

Figure 10. SEM/SE images of green microblind-flange parts made of (a) Al58M1, (b) Al-MWCNT58M1 illustrating the replication of concentric ring structure, (c) Al62M1, (d) Al-MWCNT58M1SA5, (e) Al62M1SA1.6, and (f) Al62M1SA5 without the replicability of the rings (shaped at $230{ }^{\circ} \mathrm{C}, 8.5$ $\mathrm{MPa}$ for $30 \mathrm{~min}$ by dark blue elastomer die).

Microstructural analysis showed that there are more dark regions in Al58M1 green parts (Figure 11a) than in Al-MWCNT58M1 ones (Figure 11b,c), i.e., the homogeneity of green parts containing MWCNT increased. Meanwhile, the microcrack formation (illustrated in Figure 11a by a white arrow inset) in the green parts after demoulding diminished. This improvement 
could be attributable to the nanoreinforced binder material that reduced the demolding stresses, i.e., the strengthening effect of the nanotubes in the polymeric materials [30]. A longer holding time also helped in homogenizing the green parts (Figure 10c). The problems associated with the SA addition (Figure 10d-f) could be due to the separation of the powder-binder at very low viscosities [16] and this was more pronounced in the presence of MWCNT (Figure 10d) rather than for higher powder content. With regard to shaping and homogeneity of 316L green parts, it was obtained and also increased with MWCNT addition (Figure 11e,f).

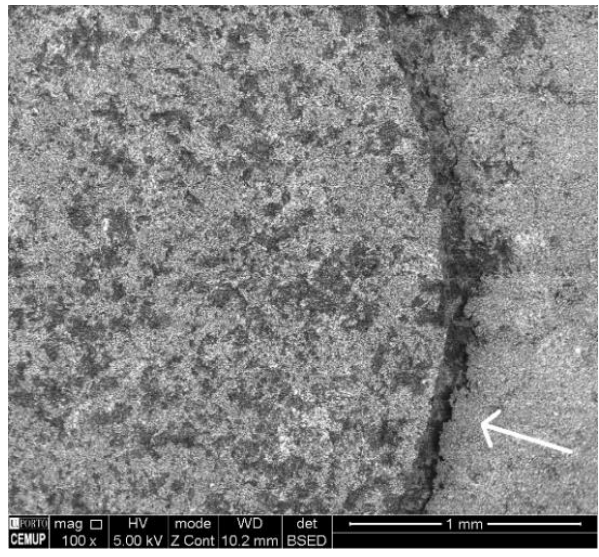

(a)

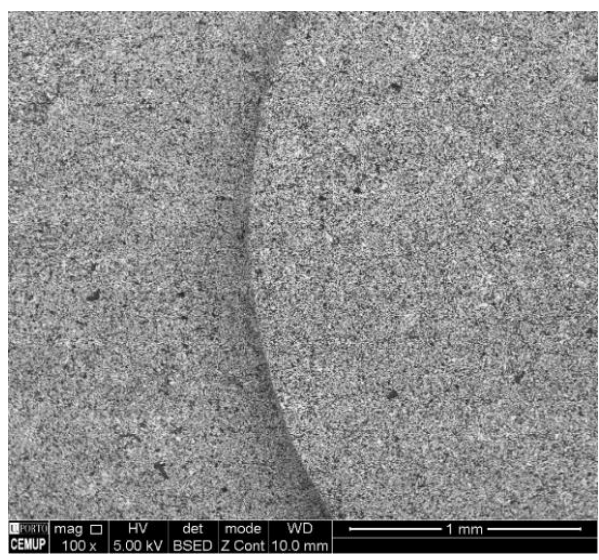

(c)

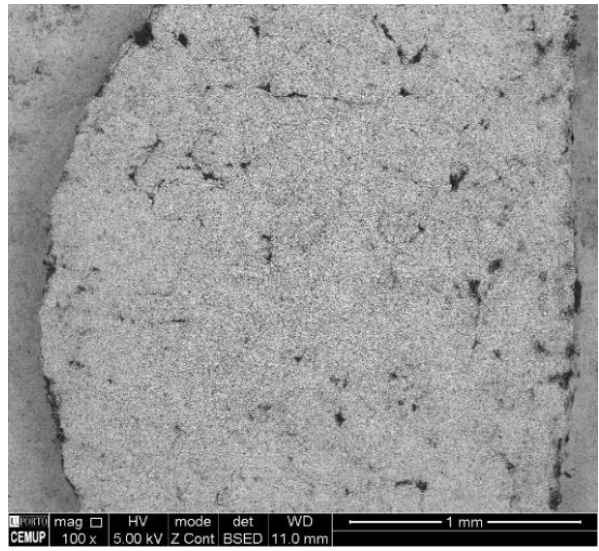

(e)

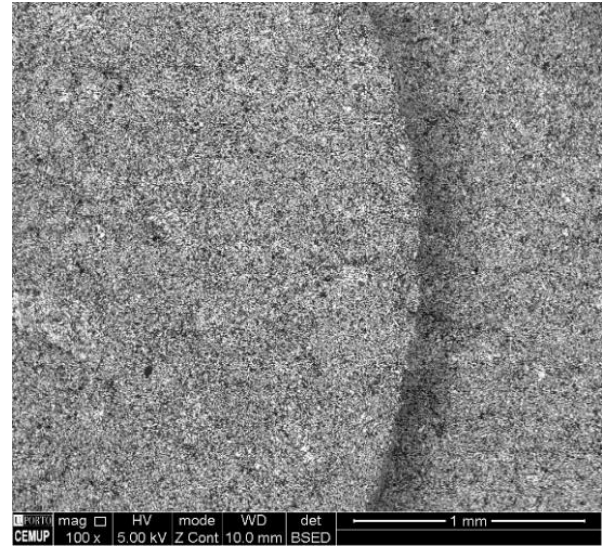

(b)

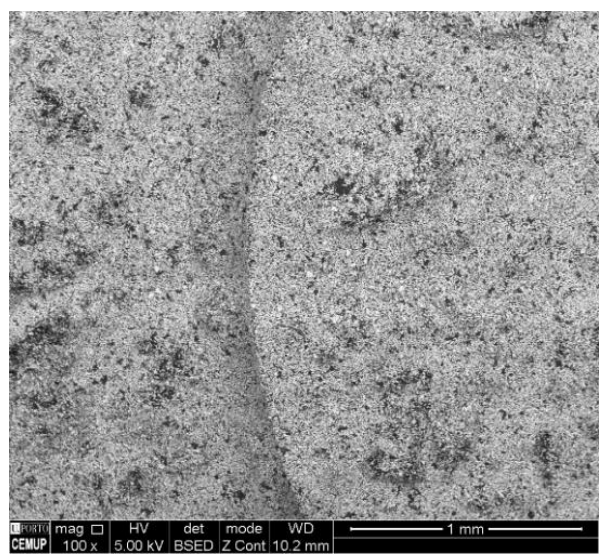

(d)

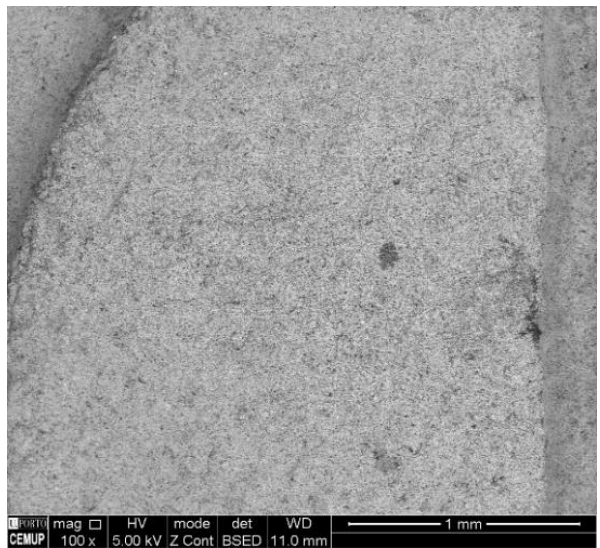

(f)

Figure 11. SEM/BSE images showing the distribution of powder-binder in green microblind-flange parts made of: (a) Al58M1 and (b) Al-MWCNT58M1, shaped at $230{ }^{\circ} \mathrm{C}, 11.3 \mathrm{MPa}$ for $15 \mathrm{~min}$; (c) Al-MWCNT58M1 and (d) Al-MWCNT58MSA5, shaped at $230^{\circ} \mathrm{C}, 11.3 \mathrm{MPa}$ for $45 \mathrm{~min}$; (e) 316L60M1 and (f) 316L-MWCNT60M1, shaped at $230{ }^{\circ} \mathrm{C}, 11.3 \mathrm{MPa}$ for $30 \mathrm{~min}$ by transparent elastomer. 
The IFM analyses (Figures 3 and 12) revealed that the surface roughness parameters (Sa and Sz) of the green parts are larger than those of their dies (Table 4). Dimensional changes are attributed to the plastic deformation of the elastomer die during the shaping process and/or the feedstock shrinkage after cooling. Moreover, this is seen that the roughness of the green parts (Figure $12 b, c)$ was also influenced by the number of times the elastomer die was used, (Figures 3 and 12) this change either has happened due to the die erosion or other changes occurred in the elastomer die. The reason for the latter was confirmed by an increase in its hardness (from $38 \pm 1$ Shore $\mathrm{A}$ in the pristine condition to $40 \pm 1$ Shore A after shaping), being affected by temperature and compaction during shaping process. This being the case that, the elastomer die has become stiffer than its pristine state leading to new dimensions and roughness (Table 4). This indicates that micro hot embossing process with elastomer die is suitable only for very small series production.

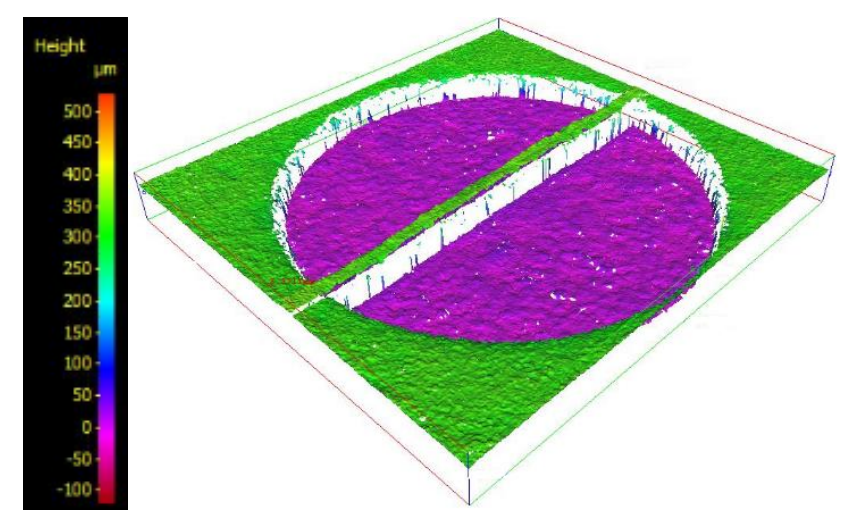

(a)

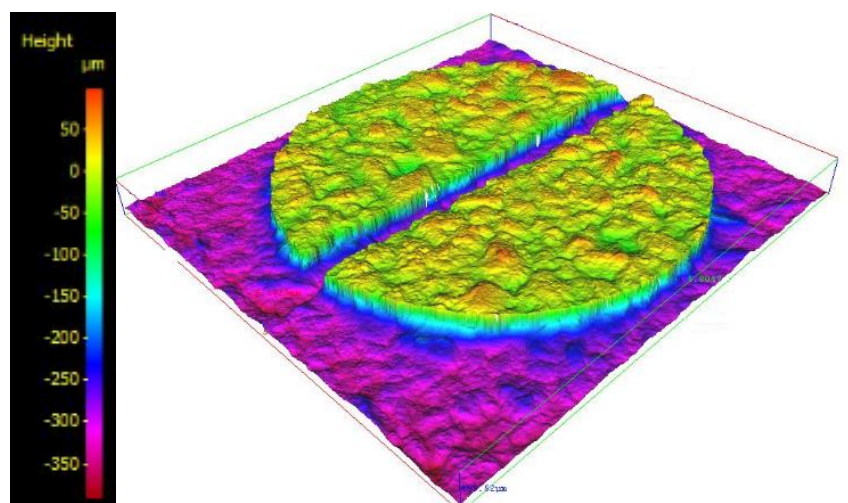

(b)
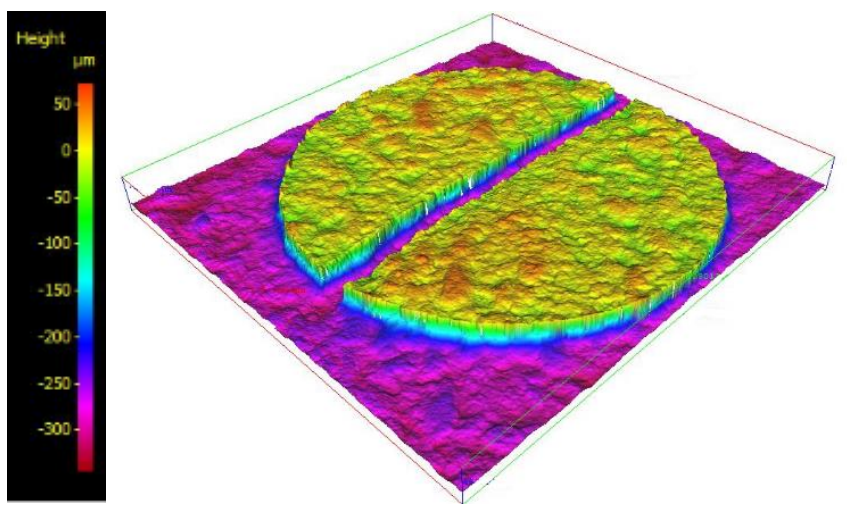

(c)

Figure 12. Roughness maps obtained by IFM analyses: (a) transparent elastomer die used twice for replicating green microchannel-half-flanges parts, (b) green part shaped by pristine die and (c) by the used die (Al-MWCNT58M1 parts shaped at $11.3 \mathrm{MPa}$ and $230^{\circ} \mathrm{C}$ for $30 \mathrm{~min}$ ). 
Table 4. Dimensional characteristics (in $\mu \mathrm{m}$ ) of the used die and green parts illustrated in Figure 12.

\begin{tabular}{ccccccc}
\hline Part & Diameter & Height & Maximum Width & Minimum Width & Sa & Sz \\
\hline Used elastomer die in Figure 12a & 4870 & $324 \pm 10$ & $347 \pm 21$ & $248 \pm 12$ & 6 & 106 \\
Green part in Figure 12b & 4856 & $266 \pm 6$ & $403 \pm 14$ & $246 \pm 12$ & 17 & 161 \\
Green part in Figure 12c & 4843 & $271 \pm 54$ & $362 \pm 33$ & $283 \pm 27$ & 13 & 107 \\
\hline
\end{tabular}

Regarding this study, the authors ensures the reproducibility of these results indicating that green $\mathrm{Al}$ and 316L (with and without MWCNT) parts without defects were produced by optimized feedstocks through micro hot embossing, demonstrating that the presence of MWCNT led to a better homogeneity. Moreover, dimensional and roughness changes of green parts in respect to their elastomer dies are characteristics of micro hot embossing. The future work of this study will involve debinding (in a controlled atmosphere) and sintering (in low pressure atmosphere) of these green parts, and evaluating the densification, topography and strengthening.

\section{Conclusions}

Feedstocks based on $\mathrm{Al}$ and 316L powders, with and without MWCNT, were prepared. The optimized powder concentrations were based on their CPVC values. Although the $\mathrm{Al}$ and $316 \mathrm{~L}$ powders have quite different powder characteristics, these powders presented close CPVC values. The addition of 1 vol.\% of MWCNT increased the viscosity of the feedstocks, while the SA addition reduced it. The control of the torque variations during mixing showed that the different compositions achieved a steady state during mixing for at least $17 \mathrm{~min}$. Microstructural analysis confirmed the apparent homogeneity of the feedstocks; however, MWCNT clusters in the binder were observed. Prolonging the torque mixing time for the 316L stainless steel feedstock led to a homogeneous dispersion and it did not require the extrusion process. In this study, the optimized $\mathrm{Al}$ and 316 feedstocks with $1 \mathrm{vol} . \%$ MWCNT required almost equal torque mixing values, and the feedstocks with 65 vol.\% powder concentrations as well. Producing green parts confirmed that shaping was strongly affected by the powder concentration while the viscosity reduction in the Al feedstocks, by stearic acid, was ineffective. The addition of 1 vol.\% MWCNTs improved shaping, increased the homogeneity of the green parts and the microcrack formation was eliminated without considerable topographical changes. The use of elastomer dies in the micro hot embossing process caused changes in roughness of the green part which increased according to the number of times the process was repeated.

Author Contributions: O.E. produced and characterized the feedstocks and green parts, and hardness measurement; O.E., M.T.V. and M.F.V. discussed the graphics, microstructures, topography images and hardness values. All the authors participated in the design of the experiments and cooperated in writing this paper.

Funding: This study was supported by the Fundação para a Ciência e a Tecnologia, Portugal, through PD-BD526742014 grant, and also the Add.Additive project (POCI-01-0247-FEDER-024533).

Acknowledgments: The authors would like thank Centro de Materiais da Universidade do Porto for SEM assistance and Instituto Pedro Nunes for IFM and hardness measurement.

Conflicts of Interest: The authors declare no conflict of interest.

\section{References}

1. Peng, L.F.; Deng, Y.J.; Yi, P.Y.; Lai, X.M. Micro hot embossing of thermoplastic polymers: A review. J. Micromech. Microeng. 2014, 24. [CrossRef]

2. Heckele, M.; Bacher, W.; Muller, K.D. Hot embossing-The molding technique for plastic microstructures. Microsyst. Technol. 1998, 4, 122-124. [CrossRef]

3. Fu, G.; Tor, S.; Loh, N.; Hardt, D. Micro-hot-embossing of 316L stainless steel micro-structures. Appl.Phys. A: Mater. Sci. Process. 2009, 97, 925-931. [CrossRef]

4. Sequeiros, E.W.; Neto, V.C.; Vieira, M.T.; Vieira, M.F. Hot micro-embossing: Effect of pressure on 316L metal parts. Powder Metall. 2014, 57, 241-244. [CrossRef] 
5. Sahli, M.; Millot, C.; Gelin, J.C.; Barrière, T. The manufacturing and replication of microfluidic mould inserts by the hot embossing process. J. Mater. Process. Technol. 2013, 213, 913-925. [CrossRef]

6. Sahli, M.; Millot, C.; Gelin, J.C.; Barrière, T. Development and characterization of polymers-metallic hot embossing process for manufacturing metallic micro-parts. AIP Conf. Proc. 2011, 1315, 677-682. [CrossRef]

7. Sahli, M.; Gelin, J.C.; Barriere, T. Characterisation and replication of metallic micro-fluidic devices using three different powders processed by hot embossing. Powder Technol. 2013, 246, 284-302. [CrossRef]

8. Barreiros, F.M.; Vieira, M.T. PIM of non-conventional particles. Ceram. Int. 2006, 32, 297-302. [CrossRef]

9. Hausnerova, B.; Mukund, B.N.; Sanetrnik, D. Rheological properties of gas and water atomized 17-4PH stainless steel MIM feedstocks: Effect of powder shape and size. Powder Technol. 2017, 312, 152-158. [CrossRef]

10. Bakshi, S.R.; Lahiri, D.; Agarwal, A. Carbon nanotube reinforced metal matrix composites-A review. Int. Mater. Rev. 2010, 55, 41-64. [CrossRef]

11. Ye, H.Z.; Liu, X.Y.; Hong, H.P. Fabrication of metal matrix composites by metal injection molding-A review. J. Mater. Process. Technol. 2008, 200, 12-24. [CrossRef]

12. Romero, A.; Herranz, G. Development of feedstocks based on steel matrix composites for metal injection moulding. Powder Technol. 2017, 308, 472-478. [CrossRef]

13. Supati, R.; Loh, N.; Khor, K.; Tor, S. Mixing and characterization of feedstock for powder injection molding. Materials Letters 2000, 46, 109-114. [CrossRef]

14. Barreiros, F.M.; Vieira, M.T.; Castanho, J.M. Fine tuning injection feedstock by nano coating SS powder. Met. Powder Rep. 2009, 64, 18-21. [CrossRef]

15. Emadinia, O.; Vieira, M.F.; Vieira, M.T. Effect of Reinforcement Type and Dispersion on the Hardening of Sintered Pure Aluminium. Metals 2018, 8, 786. [CrossRef]

16. Enneti, R.K.; Onbattuvelli, V.P.; Atre, S.V. Powder binder formulation and compound manufacture in metal injection molding (MIM). In Handbook of Metal Injection Molding; Woodhead Publishing: Cambridge, UK, 2012; pp. 64-92.

17. Sequeiros, E.W. Microfabricação de Componentes Metálicos por Microgravação. PhD Thesis, University of Porto, Porto, Portugal, July 2014.

18. Sotomayor, M.; Várez, A.; Levenfeld, B. Influence of powder particle size distribution on rheological properties of 316L powder injection moulding feedstocks. Powder Technol. 2010, 200, 30-36. [CrossRef]

19. Kong, X.; Barriere, T.; Gelin, J. Determination of critical and optimal powder loadings for 316L fine stainless steel feedstocks for micro-powder injection molding. J. Mater. Process. Technol. 2012, 212, 2173-2182. [CrossRef]

20. Park, S.J.; Kim, D.; Lin, D.; Park, S.J.; Ahn, S. Rheological Characterization of Powder Mixture Including a Space Holder and Its Application to Metal Injection Molding. Metals 2017, 7, 120. [CrossRef]

21. Ferreira, T.J.; Vieira, M.T. Optimization of MWCNT-Metal Matrix Composites feedstocks. Cienc. Tecnol. Mater. 2017, 29, e87-e91. [CrossRef]

22. Ferreira, T.J.; Vieira, M.T. Behaviour of feedstocks reinforced with nanotubes for micromanufacturing. In Proceedings of the Euro PM 2014 Congress and Exhibition, Salzburg, Austria, 21-24 September 2014; Available online: https://www.epma.com/publications/euro-pm-proceedings/product/euro-pm2014powder-injection-moudling-modelling-and-processing (accessed on 27 November 2018).

23. Ahmad, F.; Muhsan, A.S.; Raza, M.R. Rheological behavior of carbon nanotubes/copper feedstocks for metal injection molding. Adv. Mater. Res. 2012, 403-408, 5335-5340. [CrossRef]

24. Liang, S.; Tang, Y.; Zhang, Y.; Zhong, J. The rheologyical effect of carbon nanotubes on the iron based metal powder injection molding feedstock. Adv. Mater. Res. 2009, 79-82, 469-472. [CrossRef]

25. Gonzalez-Gutierrez, J.; Duretek, I.; Kukla, C.; Poljsak, A.; Bek, M.; Emri, I.; Holzer, C. Models to Predict the Viscosity of Metal Injection Molding Feedstock Materials as Function of Their Formulation. Metals 2016, 6, 129. [CrossRef]

26. Li, Y.M.; Liu, X.Q.; Luo, F.H.; Yue, J.L. Effects of surfactant on properties of MIM feedstock. Trans. Nonferr. Met. Soc. China 2007, 17, 1-8. [CrossRef]

27. Sahli, M.; Gelin, J.C. Development of a feedstock formulation based on polypropylene for micro-powder soft embossing process of 316L stainless steel micro-channel part. Int. J. Adv. Manuf. Technol. 2013, 69, 2139-2148. [CrossRef] 
28. Nuriel, S.; Liu, L.; Barber, A.H.; Wagner, H.D. Direct measurement of multiwall nanotube surface tension. Chem. Phys. Lett. 2005, 404, 263-266. [CrossRef]

29. Ahn, S.; Park, S.J.; Lee, S.; Atre, S.V.; German, R.M. Effect of powders and binders on material properties and molding parameters in iron and stainless steel powder injection molding process. Powder Technol. 2009, 193, 162-169. [CrossRef]

30. Spitalsky, Z.; Tasis, D.; Papagelis, K.; Galiotis, C. Carbon nanotube-polymer composites: Chemistry, processing, mechanical and electrical properties. Progress Polym. Sci. 2010, 35, 357-401. [CrossRef]

(C) 2018 by the authors. Licensee MDPI, Basel, Switzerland. This article is an open access article distributed under the terms and conditions of the Creative Commons Attribution (CC BY) license (http://creativecommons.org/licenses/by/4.0/). 